\title{
.
}

\section{EL NUEVO SIGLO Y LA ENTRADA EN LA OMC VISIÓN DESDE LA OFICINA EN SHANGHAI}

Shanghai es considerada con frecuencia como la capital económica y comercial de China. Rodeada por las provincias de Jiangsu al norte y noroeste y Zhejiang al sur y suroeste, se ubica en la próspera zona del Delta Yangtze. Aunque gracias a los $6.300 \mathrm{~km}$ de longitud de este río ha tenido tradicionalmente un acceso privilegiado al comercio, Shanghai fue un simple pueblo pesquero hasta 1842 .

La derrota de China en la primera guerra del opio llevó a la dinastía Qing a firmar en ese año el Tratado de Nankín, aceptando la apertura de cinco puertos desde los que el imperio británico pudiera comerciar libremente: Cantón, Amoy, Foochow, Ningbo y Shanghai. Fue este el primero de una serie de acuerdos entre China y otras naciones occidentales que, en poco tiempo, convirtieron a Shanghai en un importante centro comercial, dividido en concesiones autónomas no sometidas a las leyes chinas y administradas por británicos, franceses y norteamericanos.

Durante las décadas siguientes, las oportunidades de negocio ofrecidas por la metrópoli atrajeron a numerosas empresas extranjeras y a buena parte de la población de otras regiones. Fue también en Shanghai donde en 1921 el Partido Comunista Chino (PCC) celebró su

*Técnico Comercial y Economista del Estado. Versión de enero de 2018. primer congreso, que llevaría más tarde a una profunda transformación de todo el país. La invasión por las fuerzas japonesas en 1937 y el estallido de la Segunda Guerra Mundial ralentizaron la actividad de la ciudad, y en 1949 el triunfo de la Revolución Comunista supuso su cierre - prácticamente total-al exterior.

No obstante, las reformas de finales de la década de los ochenta y comienzos de los noventa, que culminaron con la adopción de una economía socialista de mercado, transformaron de nuevo a Shanghai en el motor del renacimiento comercial. El objetivo oficial de que pudiera rivalizar con Hong Kong hacia 2010 contribuyó a la atracción de inversión extranjera y en el año 2000 la economía local se convirtió en la primera de China continental en rebasar la barrera de 4.000 dólares USA de PIB per cápita.

En 1999 Shanghai presentó su candidatura como sede de la Exposición Universal de 2010, decisión que se sumó a la aspiración de Pekín de organizar los Juegos Olímpicos de 2008 y consolidó el protagonismo de ambas en la esfera internacional. El lema propuesto para la Expo 2010 era «Una ciudad mejor, una vida mejor», y se buscaba presentar a Shanghai, la ciudad más populosa de la mayor economía en desarrollo, como modelo para las urbes emergentes. 
Este fue el entorno en que en 1999 se abrió la Oficina Económica y Comercial de España en Shanghai, cuyas competencias se extendían a las provincias de Zhejiang y Jiangsu, en consonancia con la jurisdicción geográfica autorizada por el Gobierno chino para las representaciones diplomáticas establecidas en la municipalidad.

\section{El contexto económico de China}

El contexto macroeconómico de esta época viene marcado, sin duda, por el acceso de China a la Organización Mundial de Comercio (OMC) en diciembre de 2001 y por la aprobación del X Plan Quinquenal, que abarcaba el periodo 2001-2005. Este último fijaba el objetivo de crecimiento en el 7 por 100 anual y recogía ya algunos principios encaminados a reorientar la estrategia de crecimiento, promoviendo los sectores de alto contenido tecnológico y esbozando nuevas medidas de protección del medio ambiente.

La recuperación de la economía mundial, una política fiscal y monetaria expansiva, la apertura al exterior y el consiguiente incremento de la inversión extranjera facilitaban el desarrollo, pero los efectos de la crisis de las economías asiáticas y los inevitables cambios estructurales complicaban la gestión.

El cumplimiento de los compromisos asumidos tras la entrada en la OMC conllevaba, en efecto, un aumento de la competencia, la apertura de sectores tradicionalmente cerrados a la inversión extranjera, el saneamiento de los bancos y la reestructuración de las empresas públicas. Simultáneamente, la consecución de estas metas originaba una preocupación importante en el seno del Gobierno chino: el malestar social por el incremento del desempleo y la desigualdad relativa, que podía afectar a la estabilidad del país.

China contaba con más de 100.000 empresas grandes y medianas de propiedad pública, pero la mayoría incurría en pérdidas cubiertas por el Gobierno. Su participación en la producción empresarial total había ido disminuyendo desde el 75 por 100, que alcanzaba a finales de los años setenta, hasta el 28 por 100. Pese a ello, las compañías estatales continuaban proporcionando el 44 por 100 del empleo urbano. El despido de trabajadores para aumentar la competitividad se intensificó a partir de 2001, y si bien el índice de paro en las ciudades (única cifra proporcionada por las autoridades) continuó siendo inferior al 4 por 100, las estimaciones independientes apuntaban a que podía superar el 10 por 100 .

A la preocupación por las diferencias sociales se sumaba la originada por las desigualdades regionales. Por este motivo, Jiang Zemin lanzó en 1999 la consigna de «Desarrollar el oeste de China», zona en la que se concentraba el 90 por 100 de la población situada por debajo del umbral de la pobreza. El X Plan Quinquenal recogió como objetivo estratégico el desarrollo social y económico del interior del país, más sensible a los efectos de la liberalización exterior. Los sectores primario y secundario representaban en estas regiones un porcentaje del PIB mayor que en la costa, predominaba la agricultura en monocultivo y el desarrollo industrial, más lento, se había concentrado en sectores pesados de propiedad pública como la explotación de materias primas.

Esta estructura contrastaba con la de las zonas costeras, en las que había una mayor presencia del sector privado, la industria manufacturera y los servicios. El Gobierno decidió priorizar proyectos de infraestructuras que $D$ 
dinamizasen el interior y permitiesen su acercamiento progresivo a las condiciones del este del país. Entre ellos destacaban, por ejemplo, el gaseoducto Xinjiang-Shanghai, el ferrocarril al Tíbet, el trasvase del río Yangtze al río Amarillo y la transmisión de electricidad del oeste al este.

En esta situación se produjo la llegada al poder de la llamada «cuarta generación» de líderes chinos que, con el presidente $\mathrm{Hu}$ Jintao y el primer ministro Wen Jiabao al frente, asumieron el control del Partido en 2002 y del Gobierno en 2003. Su programa prometía una sociedad moderadamente próspera para la mayoría de la población hacia 2020 , la reducción de la desigualdad en la distribución personal y territorial de la renta, y el freno a la corrupción.

\section{Las relaciones bilaterales hispano-chinas}

Durante estos años, el Gobierno español se hizo eco de la coexistencia de «dos realidades contradictorias que, de no corregirse, corrían el riesgo de convertirse en incompatibles con nuestros intereses». Mientras que la región de Asia Pacífico concentraba más del 50 por 100 de la población mundial y producía en torno al 25 por 100 del PIB global, constituyendo uno de los polos más dinámicos del planeta, la presencia de nuestro país en ella era muy reducida. Las empresas españolas, sin embargo, desarrollaban desde hacía tiempo importantes proyectos y eran líderes en sectores muy relevantes en Europa, en países mediterráneos, en Iberoamérica o en Oriente Medio. Se decidió, por tanto, lanzar el Plan Asia Pacífico 20002004, que además de reforzar la presencia española en los ámbitos político y cultural, incluía entre sus objetivos prioritarios la corrección de estos desequilibrios.
La economía china representaba, ya entonces, más del 7 por 100 del PIB mundial en términos de paridad del poder adquisitivo, por lo que las relaciones con el país asiático cobraban singular importancia. Si bien el comercio bilateral había aumentado notablemente en las dos décadas anteriores, en el año 2000 nuestra tasa de cobertura se mantenía en el 12 por 100, la inversión española en el mercado chino fue de 43 millones de euros, y la de China en nuestro país se limitó a 1,7 millones de euros.

Las exportaciones se centraban en gran medida en productos químicos, electrónica e informática, material eléctrico, maquinaria y bienes de equipo, piedra natural y sus manufacturas, y las principales operaciones correspondían a proyectos aprobados con crédito mixto español. Desde 1994 China había ocupado las primeras posiciones en el ranking de países receptores de Fondos de Ayuda al Desarrollo (FAD), y las empresas españolas eran muy activas en sectores como las energías renovables - especialmente eólica-, el tratamiento de aguas y residuos, la sanidad, los sistemas de ticketing, el control de tráfico aéreo y urbano o el suministro de material rodante. En 2001 entró en vigor un nuevo Programa Financiero bienal, por valor de 710 millones de dólares USA. CESCE, por su parte, incluía a la República Popular de China en el 2. grupo, la mejor clasificación otorgada a países no industrializados. Se constataba la existencia de un buen número de proyectos en cartera, lo que, unido a las perspectivas que abría la incorporación de China a la OMC, daba lugar a un moderado optimismo.

La adhesión de China a esta organización internacional debía llevar a la supresión gradual de muchos obstáculos técnicos al comercio y a la reducción progresiva de aranceles para productos como maquinaria, automóviles, cerámica $\triangleright$ 
y cristal, textiles, prendas de vestir, calzado y pieles, cosméticos y licores. El Gobierno chino se había comprometido, además, a suavizar la legislación que restringía la inversión extranjera directa y a autorizar su acceso a la prestación de servicios en ámbitos como la banca, los seguros, las telecomunicaciones, la distribución al por mayor o la venta al por menor.

Las empresas extranjeras se enfrentaban hasta ese momento a numerosas barreras arancelarias y no arancelarias: contingentes a la importación; falta de transparencia y aplicación discrecional de la legislación; restricciones a las operaciones de comercio exterior, comercialización o distribución; complejas exigencias de homologación y certificación; violaciones de los derechos de propiedad intelectual, etcétera. En el caso específico de España, estaba también prohibida la importación de productos cárnicos y cítricos. Las expectativas sobre una mayor liberalización, si bien no exentas de un cierto escepticismo, dieron lugar a un punto de inflexión en el interés que China despertaba.

\section{La actividad de la Oficina Económica y Comercial}

Las oportunidades de negocio derivadas del tamaño de la economía china y de su mayor apertura al exterior llevaron, tanto a la Administración del Estado como a las empresas españolas, a prestarle una notable atención. Por una parte, se intensificaron las relaciones institucionales, y en el año 2000 visitaron China, entre otras muchas autoridades, el príncipe de Asturias y el presidente del Gobierno. Durante los ejercicios siguientes continuaron los viajes de altos cargos, y la Secretaría de Estado de Comercio e ICEX pusieron en marcha una intensa estrategia de promoción e información.
El innegable atractivo de un país con más de mil millones de consumidores y con un creciente poder adquisitivo hacía necesario, en primer lugar, un análisis realista y lo más riguroso posible de las distintas zonas geográficas y áreas de actividad. A pesar de la escasa precisión de las estadísticas locales, las disparidades de renta y desarrollo podían hacer engañosa la consideración de la economía china como un único mercado de gran dimensión. Por otro lado, debían identificarse los obstáculos y los riesgos que, a pesar de los compromisos adquiridos por la incorporación a la OMC, aún persistían.

La imagen que se tenía entonces de España era positiva, atribuyéndosenos las características propias de una nación europea, pero sin un conocimiento detallado de nuestra realidad. En la zona de Shanghai, la Expohabitat del año 2000 había tenido un efecto muy beneficioso sobre la percepción de productos españoles, como los materiales de construcción, el diseño o el mobiliario. No era infrecuente, por ejemplo, que en los proyectos residenciales de lujo se hiciera hincapié en el equipamiento español, y la arquitectura de nuestro país gozaba cada vez de mayor prestigio.

Las empresas españolas iban siendo cada vez más conocidas en el ámbito de las infraestructuras, gracias en buena medida al éxito de los programas financieros mencionados en el apartado anterior y a la creciente participación de nuestras compañías en iniciativas financiadas por instituciones multilaterales. China continuaba inmersa en un ambicioso plan de desarrollo, y eran frecuentes, por tanto, los contactos de la Ofecome con las autoridades responsables de las licitaciones, presentando la fortaleza de la oferta española y las posibilidades de contar con financiación pública.

Existían también oportunidades interesantes en sectores como la automoción y los $\triangleright$ 
bienes de equipo (máquina herramienta, maquinaria textil, maquinaria para procesado y embalaje de madera, o maquinaria de obras públicas), en especial en los segmentos de tecnología media. Ya entonces se percibía el interés de la competencia china en atraer know-how y su rápida capacidad de aprendizaje. El creciente consumo de vinos, aceite de oliva, moda, piel y calzado o cosmética aconsejaba reforzar la promoción en estas áreas, y también las telecomunicaciones, la banca, el turismo y los servicios profesionales atraían a un buen número de empresas.

Las actividades de promoción en los sectores citados se reforzaron con numerosas campañas de comunicación. Se colaboraba además con frecuencia con las televisiones locales interesadas en emitir reportajes sobre España y se prestaba la mayor atención posible a las solicitudes de la Administración china sobre asesoramiento en cuestiones diversas como la defensa de su candidatura para la Expo 2010 o la formación de funcionarios.
Por último, existía una estrecha relación con instituciones como la Cámara de Comercio de España en China, que en el año 2000 había abierto la división de Shanghai, o la Cámara de Comercio Europea, que asimismo había establecido recientemente una delegación en la ciudad. Se valoraba también muy positivamente la colaboración con CEIBS (China Europe International Business School) que, fundada en 1994 por el Gobierno municipal de Shanghai y la Unión Europea gracias a un fuerte apoyo español, disponía de una extensa red de antiguos alumnos estratégicamente situados en las mejores empresas e instituciones del país.

Fue, en síntesis, un periodo en el que muchas empresas se aproximaron por primera vez al mercado chino, su economía experimentó un marcado proceso de apertura al exterior y la Administración española reforzó su compromiso institucional. Una etapa de aprendizaje en múltiples sentidos que, como sin duda ocurre en muchas otras relacionadas con el país, resultó de enorme interés. 
